\title{
Saberes e práticas tradicionais em movimento: a comunidade do Maracanã na rota de um projeto global
}

\author{
Traditional knowledge and practices in movement: yhe community of \\ Maracanã on the route of a global project
}

Joaquim Shiraishi Neto - Doutor em Direito pela UFPR. Professor Visitante da UFMA, vinculado ao Programa de Pós-Graduação em Ciências Sociais (PPGCSoc-UFMA) e Bolsista de produtividade do CNPq. E-mail: shiraishineto@gmail.com

Rosirene Martins Lima - Doutora em Meio Ambiente e Desenvolvimento pela UFPR (MADE-UFPR). Docente do Curso de Ciências Sociais da Universidade Estadual do Maranhão (UEMA-CCSA). Coordenadora do Grupo de Pesquisa "Cidade, Território e Meio Ambiente". E-mail: rosirenelima@uol.com.br

Luzinele Everton de Alcobaça - Mestre em Ciências Sociais pela UFMA e Doutoranda em Antropologia pela Universidade Federal de São Carlos (UFSCar). E-mail: lu.zinele@ hotmail.com

\section{Resumo}

A comunidade do Maracanã, localizada na zona rural de São Luís, MA, desde a última década, vem sofrendo um processo de asfixia, decorrente da expansão urbana da cidade, com a construção, no seu entorno, de conjuntos do Programa Minha Casa Minha Vida. Os processos de devastação e o adensamento populacional da área do Maracanã produziu uma nova ordem de problemas, que reconfigurou o espaço, trazendo consigo novos desafios aos "antigos moradores". Assim, este artigo objetiva refletir sobre esses processos em curso, que implicam na reorganização das maneiras de viver da comunidade, coadunadas em saberes e práticas socialmente construídas. A metodologia utilizada se fundamentou em técnicas de observação direta e conversas com os moradores da comunidade, realizadas em distintos contextos. Os esforços em analisar as situações empiricamente observadas revelam o caráter preliminar da pesquisa.

\section{Palavras-chave}

Comunidade do Maracanã. Saberes e Práticas Tradicionais. Modelos de Natureza. Expansão Urbana.

\begin{abstract}
The Maracanã community, located in the rural area of São Luis, MA, since the last decade, has suffered a suffocation process, due to the urban expansion of the city, with the construction, in its surroundings, of the My Home My Life Program. The processes of devastation and the population density of the Maracanã area produced a new order of problems, which reconfigured the space, bringing with it new challenges to the "old community residents". Thus, this article aims to reflect on these ongoing processes, which involve the reorganization of community ways of living, consistent with socially constructed knowledge and practices. The methodology used was based on techniques of direct observation and conversations with the residents of the community, carried out in different contexts. Efforts to analyze empirically observed situations reveal the preliminary nature of the research.
\end{abstract}

\section{Keywords}

Community of Maracanã. Knowledge and Practices. Models of Nature. Urban Expansion. 


\section{INTRODUÇÃO}

$\mathrm{Na}$ última década, a comunidade do Maracanã, localizada no município de São Luís, MA, vem sofrendo transformações resultantes da construção, nos seus arredores, de 4 (quatro) conjuntos do Programa Minha Casa Minha Vida (PMCMV).

A edificação destes conjuntos do PMCMV demarca 2 (dois) períodos na vida da comunidade. Os problemas e os conflitos vividos atualmente além de evidenciar uma espécie de estranhamento com o "outro" (com os moradores dos conjuntos, recém-chegados), sinalizam rupturas com um passado recheado de boas histórias e lembranças de sossego e "calmaria". Tais períodos, que se interseccionam e se cruzam correspondem a de dinâmicas territoriais. Entretanto, como o objeto da pesquisa não era a comunidade em si, mas a compreensão dos "processos socioespaciais na Região Metropolitana de São Luís"1 , as experiências com essas "histórias locais" da comunidade que vieram à tona nesse período da pesquisa foram "deixadas de lado".

Aqui recuperadas, as conversas ${ }^{2}$ e os encontros com moradores da comunidade do Maracanã, que ocorreram em distintos períodos, condições e contextos $^{3}$, permitiram várias "descobertas", as quais, sistematizadas, compõem este texto. $\mathrm{O}$ artigo às vezes em tom de relatório expõe, portanto, o caráter preliminar e incipiente da pesquisa em andamento, que se revela a partir das experiências de "histórias locais", cruzadas e entrecruzadas por "projetos globais".

As noções de "historias locais" e "projetos globais", tomadas de Mignolo (2003), é aqui adaptada para se referir as dinâmicas dos processos que está submetida a comunidade do Maracanã, estabelecida desde o século XVII ${ }^{4}$.

1 Um dos resultados parciais da pesquisa foi a produção de um texto sobre as disputas pela cidade de São Luís, que deslocou as formas tradicionais de poder. A propósito, recomendamos Shiraishi Neto, Lima e Serra (2018).

2 Recorremos a Walter Mignolo sobre a conversa como um método da pesquisa: "Por conversações, não me refiro afirmações que podem ser gravadas, transcritas ou usadas como documentos. $\mathrm{Na}$ maior parte dos casos, as conversações mais significativas consistem em comentários sobre um acontecimento, um livro, uma ideia, uma pessoa que a gente viu de passagem. Se trata de conhecimentos que não podem ser transcritos, conhecimento que vai e vem, porém que permanece com um e introduz mudanças em determinadas analises." (MIGNOLO, 2003, p.10 - tradução livre dos autores).

3 Desde 2015, temos visitado a comunidade do Maracanã. Inicialmente, para acompanhar os trabalhos de pesquisa dos bolsistas do Programa de Iniciação à Pesquisa (PIBIC), do curso de Ciências Sociais da UEMA. Em outro período, levantando informações para o projeto de pesquisa "Processos socioespaciais na região metropolitana de São Luís: disputas territoriais e conflitos socioambientais" (UEMA- CCSA). Ao longo de todo esse período, retornamos em diversas ocasiões à comunidade para visitar as pessoas, com o intuito de participar de festas e reuniões.

4 À época, a comunidade do Maracanã fazia parte das várias aldeias indígenas do Tupinambás na ilha do Maranhão ("Upaon-Açu”) (D’ABBVILLE, 1975); embora tal fato seja desconhecido 
Por sua vez, os "projetos globais" explicitam distintas representações da comunidade do Maracanã, sendo que a percepção que serviu para orientar a construção dos 4 (quatro) conjuntos do PMCMV é de uma população "desprovida de bens e cultura", situado na zona rural de São Luís, sem interesse econômico para o capital.

Os estudos de Wacquant (2001), aqui utilizados, sobre os "espaços marginais" são valiosos, na medida em que nos permite compreender os interesses que dominam a configuração do espaço urbano. Em um contexto de financeirização da economia esses locais de isolamento e exclusão tem uma função socioespacial “[...] o armazenamento de uma população excedente sem utilidade política e econômica identificável [...]” (WACQUANT, 2001, p. 11).

Igualmente atuais são as reflexões de Achille Mbembe (2006). O estado de exceção econômica, sacralizado, no Brasil, por um golpe parlamentar midiático, que destituiu uma legitimamente presidenta, submete a população a um poder difuso, nem sempre estatal, inseridos em uma relação econômica da morte: "fazer viver ou deixar morrer". Essa "nova forma" de controle e gestão da vida é denominada por Achille Mbembe de "necropolítica".

Neste "espaço marginal", da periferia, da periferia do capitalismo, a comunidade do Maracanã é "envolvida" por um poder econômico difuso que determinou a construção dos conjuntos, em problemas e conflitos, que resultam em todo tipo de violência a essa comunidade. Como se não bastasse os impactos gerados pela construção dos conjuntos, problemas sociais graves revelam os resultados de uma política habitacional ditada pelos interesses do capital global. O PMCMV, sublinha Rolnik (2015) ${ }^{5}$, convergiu os interesses do setor imobiliário, já cevados do capital financeiro, e a política do governo federal.

Se em um primeiro momento, os conflitos poderiam ser percebidos como produto de diferentes "práticas socioespaciais" imbuídas de formas de representação da natureza e da própria cidade, tal como as pesquisas desenvolvidas por Acselrad (2004) ${ }^{6}$, neste período mais recente, os conflitos na comunidade

pelos "antigos moradores" que afirmam que a comunidade do Maracanã se originou de um "antigo quilombo".

5 Raquel Rolnik (2015) recorda que os empresários do setor imobiliário, liderados pela Gafisa, atingidos pela crise de 2008, fizeram um lobby junto ao Ministério da Fazenda para que o governo federal implementasse um "pacote habitacional" nos moldes do programa mexicano de habitação, inspirado no modelo chileno de Pinochet. A política econômica anticíclica adotada por meio do PMCMV, lembra Rolnik, fortaleceu os setores imobiliários, em especial, as incorporadoras, que se transformaram no principal agente da política habitacional no Brasil.

6 As pesquisas sobre esses conflitos são muitas no Brasil, dentre tantas, sugerimos a de Lima (2008a). A situação analisada em Curitiba em muito se aproxima da estudada, pois, assim como aqui, ela identificou a presença de uma organização criminosa disputando o controle sobre o território. Ver também Lima e Shiraishi Neto (2016). 
resultam de disputas, envolvendo o controle territorial, a partir da ação de uma organização criminosa, autodenominada "Bonde dos 40" , que expande o controle de seu território para além dos conjuntos do PMCMV nos espaços da comunidade do Maracanã. Sob a base do medo e da violência, o "Bonde dos 40" se impõe aos moradores dos conjuntos. As pichações do "Bonde dos 40" no conjunto Amendoeiras I, por exemplo, tais como: "Proibido Roubar. Lembra. Pena de Morte. B.40“, tem a clara intenção de, por meio de intimidação, impor unilateralmente regras de convivência aos moradores.

Como visto, essas dinâmicas territoriais vividas pela comunidade do Maracanã compreendem inúmeras questões que possibilitam infinitas abordagens. O recorte específico do artigo, porém, é singelo diante de tantos problemas, já que objetiva refletir sobre os saberes e as práticas tradicionais, que organizam a vida na comunidade, face aos desafios que lhes são colocados por esses "projetos globais".

Para cumprir este objetivo, o artigo se divide em 3 (três) tópicos. O primeiro intitulado "A 'economia da juçara': saberes e usos da natureza", procura analisar a organização das "práticas extrativistas" da economia da juçara e não do açaí, como é salientado pelos moradores da comunidade ${ }^{8}$. No caso, a sua relevância não se restringe aos aspectos meramente econômicos, mas na compreensão da importância que assume os vínculos afetivos criados.

Já no tópico segundo, "Festas, rezas e cânticos", busca-se articular a "economia da juçara" com as diversas práticas culturais e religiosas existentes na comunidade. Tais práticas, que organizam a vida, sinalizam para uma indissociação dos elementos da natureza com a dimensão religiosa.

"Nós e os Outros: 'histórias locais' e 'projetos globais"” se constitui do último tópico do trabalho. Nele, o objetivo é recuperar as discussões em torno

\footnotetext{
As informações obtidas a partir de uma conversa com o advogado criminalista, Nonato Masson, do escritório de advocacia Onidayô. Ele nos relatou que o "Bonde dos 40" nasceu por volta de 2007, organizado por presos do presídio de Pedrinhas, oriundos dos bairros da Liberdade e Vila Embratel, de São Luís, MA. Segundo Masson, esses presos se organizaram diante das "humilhações" que sofriam dos membros do Primeiro Comando do Maranhão (PCM), outra facção criminosa de Pedrinhas. Outras informações a respeito do "Bonde dos 40", PCM e sistema penitenciário do Maranhão podem ser lidas em Almeida e Masson (2014).

$8 \mathrm{Na}$ "verdade", cientificamente, a planta é designada de açaizeiro e o açaí (euterpe oleracea) é seu fruto. Há diferenças entre o açaí e a juçara (euterpe edulis), apesar de serem muito parecidos. Segundo o conhecimento científico, o açaí tem uma oferta de poupa maior. Da raiz do açaizeiro pode nascer até quatro palmeiras, enquanto que da raiz da juçara só nasce uma. A forma de uso e consumo dos frutos também definem as diferenças entre o açaí e a juçara. M. E. nos relatou que o açaí é tomado como suco e a juçara tem o acréscimo da farinha de mandioca, peixes, camarões e outros acompanhamentos (conversa realizada em 06.01.2018). Tais distinções, tanto ressaltadas nas conversas, é um elemento que suscita curiosidade no que diz respeito aos saberes e representações que envolvem essa palmeira e o manejo de seus frutos na comunidade.
} 
da comunidade do Maracanã no contexto de uma urbanização expandida, que desconhece outras formas de vida na cidade de São Luís. O "alisamento do território" é a expressão mais adequada para descrever os processos econômicos em curso no Maranhão contemporâneo. Os conflitos que resultam da escassez dos juçarais, dos buritizais e das águas desafiam os moradores a reinventar novas formas de usos e convivências.

\section{A "ECONOMIA DA JUÇARA": SABERES E USOS DA NATUREZA}

A "economia da juçara" é um dado relevante para se compreender a maneira de como se organiza a vida na comunidade do Maracanã. Quem visita o Maracanã fica encantado com os inúmeros juçarais, que se espalham por toda área, situados nos fundos das residências e na beirada das ruas, no meio de riachos, córregos e nascentes que atravessam os quintais das casas.

A "festa da juçara" realizada há mais de 50 anos (em 2017, foi realizada a 48 a edição da festa) no mês de outubro, pico da safra, que ocorre entre os meses de setembro e outubro, expressa a importância da "economia da juçara" para a comunidade que se envolve na sua realização. Nela, várias atividades acontecem, além da venda da juçara, comidas típicas e artesanatos, os grupos de cultura local aproveitam para fazer as suas apresentações (tais como: a dança portuguesa, o boi do maracanã, o tambor de crioula etc.).

Neste contexto, a análise da "economia da juçara" não pode ficar reduzida à compilação de dados estatísticos relacionados ao volume de produção da juçara, como foi observado em pesquisas na região envolvendo outros produtos extrativos como seringa, castanha e babaçu. As discussões em torno do "fim do extrativismo" na Amazônia e a emergência do movimento dos seringueiros e das quebradeiras de coco babaçu, por exemplo, corroboram com os argumentos assinalados, já que os esquemas interpretativos do que é designado por “economia extrativa", ao compartilhar de um mesmo quadro geral, tendem a esvaziar os conteúdos das relações históricas vividas (OLIVEIRA FILHO, 1979) ${ }^{9}$. Os estudos mais recentes sobre esses grupos sociais designados como povos e comunidades tradicionais, que emergiram nas últimas décadas, demarcam uma diversidade de existência de formas coletivas em suas relações com a natureza e a terra (ALMEIDA, 2008), que ensejam distintos saberes e práticas tradicionais ${ }^{10}$.

\footnotetext{
9 João Pacheco Oliveira Filho está se referindo a uma pesquisa realizada por Roberto Santos (1980) sobre a economia da seringa na Amazônia. A pesquisa de Jair Amaral Filho (1990), que envolveu a economia do babaçu, por sua vez, embora fundamentada em outro referencial teórico, apresentada resultados muito parecidos o "fim da economia extrativa".

10 As práticas extrativas do babaçu apresentam especificidades, que se distinguem dos seringueiros,
} 
No Maracanã, os problemas recentes em torno da "economia da juçara", que se desenvolve no âmbito das unidades familiares, vêm despertando uma grande preocupação por parte dos moradores, pois têm prejudicado a vida de toda a comunidade. A gradativa diminuição da produção que tem afetado o consumo das famílias, afeta também as relações socais e os cuidados com os juçarais, que têm se redobrado. Em muitos pontos observamos a exuberância da vegetação nativa, cerrada e fechada, porém, em outros, é visível o aterramento dos cursos d'água, o esgoto a céu aberto e a ampliação de áreas desmatadas.

\section{Mapa 1 - Comunidade do Maracanã e os 4 conjuntos do PMCMV}

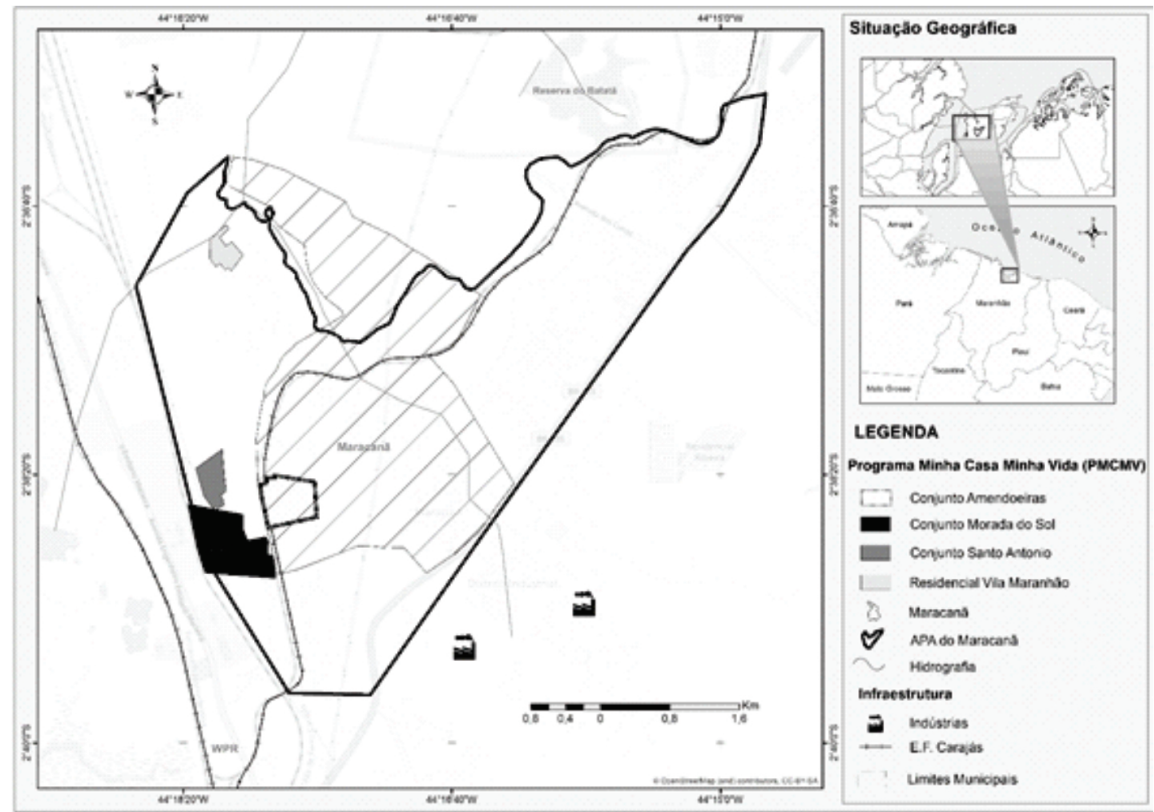

Fonte: Grupo de Pesquisa Cidade, Território e Meio Ambiente (CITEMA).

Nas conversas, os moradores relatam que os problemas ambientais, que devastam os juçarais, decorrem da construção dos 4 conjuntos do PMCMV. Entre os moradores, várias são as denúncias como esta: "A ETE (estação de tratamento de esgoto) do conjunto Amendoeiras I quebrou e passou mais de 15 dias jogando o esgoto direto nos riachos e alagados. Ela só foi consertada após muita insistência nossa e de uma denúncia ao Ministério Público” (conversa com

como foi observado por Shiraishi Neto (2017). A extensão das áreas das reservas extrativistas criadas na região evidencia a diversidade das práticas. Enquanto que para os seringueiros a apropriação e o uso das árvores de seringa ocorre de forma privada pelas famílias, para as quebradeiras de coco a apropriação e uso das palmeiras é comum, consoante capacidade e necessidade de cada família. A propósito da emergência dos vários grupos sociais designados por povos e comunidades tradicionais, recomendamos Shiraishi Neto (2010). 
C. R. M., realizada em 06.01.2018). Continua a moradora, agora, expressando toda a sua tristeza "As pessoas não querem mais comprar o buriti aqui do Maracanã, porque o buriti cai maduro no alagado e assim fica contaminado. É triste isso. Depois desses conjuntos a vida piorou muito aqui” (conversa com C. R. M., realizada em 06.01.2018).

Segundo os moradores, os problemas se iniciaram, ainda, quando da terraplanagem dos terrenos para a construção dos conjuntos, em antigas fazendas. A terraplanagem, que envolveu um conjunto de ações para planar o terreno, levou entulhos, galhos, terras... para os córregos, riachos e nascentes ${ }^{11}$ utilizados pela comunidade. A operação, além de tornar a água imprópria, levou a morte de vários cursos d'água, prejudicando os juçarais: "Infelizmente os juçarais estão se acabando por causa das construções” (conversa com S. R., realizada em 10.06.2017) ${ }^{12}$.

A escassez dos frutos vem causando outra ordem de conflitos que até então inexistia na comunidade, como o "furto da juçara". Isso, por exemplo, tem prejudicado a qualidade do produto que é comercializado na "festa da juçara". M. L. nos relatou a importância atribuída à "juçara local” que, segundo ela, tem maior qualidade pela colheita do fruto ainda maduro, o que seria um diferencial em relação à "juçara de fora", aquela que é importada de outros estados, "apanhada quase verde" (conversa realizada em 06.01.2018).

Os proprietários dos juçarais precisam ficar de olho, cercar ou contratar alguém para tomar conta, pois senão vão ficar sem a juçara. Como as pessoas que furtam desconhecem os ciclos da natureza, geralmente coletam a juçara verde, que é ruim para o consumo. Hoje, tem muito ladrão de juçara. Eles andam com um gancho, cortam os cachos com frutos verdes e maduros. Os donos das juçaras estão precisando comprar a juçara. GN (conversa com E., realizada em 20.05.2017).

No caso, observamos que a maioria dos juçarais pertencem a uma ou mais famílias. Os que se localizam nos quintais, geralmente, no fundo das casas, adentram nos terrenos vizinhos das outras famílias, isto é, não existem cercas delimitando as divisas entre os terrenos. Os cuidados com os juçarais e a distribuição da produção são, portanto, compartilhados entre as famílias que deles fazem uso. Ouvimos de uma senhora que a juçara coletada no quintal de sua casa serve para presentear os "filhos de santo" do terreiro de umbanda (conversa com S. J., realizada em 13.01.2018).

11 A extensa rede hidrográfica que compõe a bacia do Maracanã foi descrita por Cysne, Santos e Pereira (2010).

12 Esses problemas ambientais, assim como tantos outros relatados, serviram para a comunidade se organizar em torno de uma agenda, com denúncias e reivindicações, que foram encaminhadas à Secretaria de Estado do Meio Ambiente e Recursos Hídricos (SEMA). 
Nos espaços dos quintais, as juçaras e os buritis $^{13}$ se misturam à vegetação nativa, às árvores frutíferas e às plantas medicinais, que são cuidadosamente cultivadas pelas famílias de forma muito particular, especificamente, pelas mulheres, que se responsabilizam por essa obrigação. Os cuidados com a natureza são delegados pelas famílias às mulheres, que devem repassar esse conhecimento aos mais jovens, embora sejam poucos os que realmente se interessam, segundo informações.

Neste contexto, os quintais se constituem em espaços de convivência e de trocas entre as famílias, vizinhos e parentes. Os quintais são espaços também de diversão onde os adultos se juntam para comer, beber e ouvir música (reggae e "brega"); sendo que no período da pesquisa éramos recebidos nos quintais" As conversas, na maioria das vezes, interrompidas com a chegada de vizinhos, parentes ou crianças que brincavam no lugar. Em várias oportunidades, a conversa era interrompida para que a moradora pudesse nos indicar no quintal onde e como eram feitas as "coisas". As lembranças da infância eram recorrentes nestes momentos da conversa.

Com a escassez da juçara, o fruto passa a ser objeto de cobiça diante de seu valor econômico no mercado local. As situações de "furto de juçara" revelam um dado novo para a comunidade, em que os frutos eram compartilhados ou mesmo comercializados, na medida da necessidade das famílias para complementar a renda familiar.

Os "furtos"15, realizados por pessoas estranhas à comunidade, prejudicam os juçarais, já que o fruto é coletado verde, impróprio para o consumo e sem os cuidados necessários, desrespeitando os ciclos naturais para o desenvolvimento de novas palmeiras.

A coleta da juçara, aqui descrita, começa com a preparação da "pêa", um cordão feito de saco de nylon. Envolvendo os pés, o instrumento facilita a movimentação pelo caule da palmeira. $O$ uso da vara com um gancho na ponta ajuda alcançar os cachos mais altos, que são identificados pela coloração

13 Os buritizais que se encontram no meio dos juçarais também são consumidos, tanto os frutos, com os quais se produz o suco e o doce, como as palhas, que são utilizadas artesanalmente para confecção de bolsas e sacolas comercializadas em São Luís.

14 Para os moradores do Maracanã, os quintais têm a sua importância na vida da comunidade. Em contextos parecidos, Lima (2008a) descreve os usos dos quintais para as famílias de trabalhadores rurais residentes na cidade de Imperatriz, MA.

15 As situações de "furto do coco de babaçu" também foram observadas por Almeida, Shiraishi Neto e Carvalho (2005). A escassez do babaçu decorrente da valorização do coco para a produção do carvão de babaçu para atender as demandas das indústrias de ferro gusa na região gerou inúmeros conflitos envolvendo as quebradeiras de coco e os catadores. Os catadores, recrutados entre os trabalhadores desempregados das cidades da região, desconhecem os ciclos da natureza. Ao apanhar os cocos verdes, que se encontram nos cachos, interferem na reprodução das palmeiras nativas. 
dos frutos. Os conhecimentos implicados na colheita e manejo dos frutos são repassados de geração à geração pela observação, oralidade e prática cotidiana (conversa com F. E., realizada em 13.01.2017).

As crianças aprendem desde cedo com os adultos a identificação dos frutos maduros, a forma de coletá-los na palmeira, retirada dos frutos dos cachos, "debulhar", a seleção entre os verdes e os maduros e a extração da polpa ${ }^{16}$. O uso dos sentidos é imprescindível para o aprendizado e a realização de tais atividades que envolve a coleta da juçara. Ver, tocar e degustar, como foi observado em algumas ocasiões, são atos que passam por um longo período de aprendizado, que explica, como a coleta cuidadosamente realizada, é algo considerado aparentemente tão "simples" e "natural".

A "naturalidade" e "simplicidade", que envolvem o ato da coleta da juçara, fazem desse tipo de trabalho algo menor, se comparado às atividades que implicam o uso de tecnologias. Tais formas de conhecimento, lembra Escobar (2007), não eram apenas consideradas nulas, mas também eram tidas como obstáculos ao desenvolvimento das sociedades modernas ${ }^{17}$.

\section{FESTAS, REZAS E CÂNTICOS}

Respondendo ao convite de uma moradora do Maracanã, comparecemos à festa de Reis, no início do mês de janeiro. A festa em questão combina elementos do cristianismo católico com outras tradições. Logo que chegamos na casa de B. S. J. observamos o cuidado e os detalhes com a organização do presépio, enfeitado com as plantas cultivadas no local e palhas de coqueiro, que serão queimadas após a festa em um ritual denominado "queima de palhinha"18.

16 Atualmente, a polpa é produzida por meio de uma máquina específica. Ela tritura a casca do fruto, produzindo mais poupa em menos tempo. Esse método vem se popularizando e os produtores locais, principalmente os mais jovens, estão aos poucos deixando de lado a forma mais "rudimentar" de produção da poupa da juçara. Essa tarefa, engloba pôr os frutos na água sob o sol e esperar até que a casca esteja mais flexível. Depois, uma garrafa de vidro cheia de água (para ficar mais pesada) é usada para socar os frutos dentro de uma vasilha e, assim, extrair toda a poupa. Para os mais velhos, esse método dá uma maior qualidade final ao produto, diferentemente da máquina, onde o caroço não é triturado e misturado à poupa, o que melhora o sabor (conversa com S. E. M., realizada em 13.01.2018).

17 No âmbito do direito internacional, após a edição da Convenção sobre a Diversidade Biológica (CDB) e do Protocolo de Nagoya, foi construído, entre os países, um consenso sobre a necessidade de se proteger esse tipo de conhecimento tido como tradicional. Pena que no Brasil, os esforços em regulamentar tais direitos sejam pífios diante de um governo que mais se preocupou em proteger os direitos das indústrias e das empresas que sempre fizeram uso desse saber considerado "subalterno".

18 A "queima da palhinha" é realizada em momento posterior às festas de reis, de acordo com o calendário da família, que escolhe uma data significativa para fazê-lo. É quando a família e os convidados se reúnem para desmontar o presépio. Enquanto as peças permanentes são guardadas para o natal seguinte, as palhas de palmeiras que foram utilizadas para adornar o 
Segundo um dos organizadores, a cerimônia de Reis mistura cânticos, rezas e ladainhas, cantadas em latim. As ladainhas são cantadas em latim por uma rezadeira da comunidade, que atende os chamados, colaborando com a diversidade de festas religiosas na comunidade.

Contudo, não pudemos acompanhar toda a cerimônia da festa de Reis, perdemos a parte em que moradores se caracterizam de rei e rainha, mas identificamos a organização e os afazeres. Ali na casa de B. S. J., de 85 anos, um salão era cuidadosamente preparado para a cerimônia que aconteceria no período da noite, na cozinha da casa, os parentes e vizinhos preparavam a comida que seria servida aos participantes, independentemente de sua condição ou credo religioso. A fartura da comida oferecida na festa a todos os presentes tem, sobretudo, o sentido de agregar e de "manter a casa cheia, com muita participação e alegria".

A comida e a bebida (incluindo bebidas alcoólicas), bem como todo trabalho que envolve a sua preparação, resultam de doações recebidas durante o ano. Para B. S. J. e sua filha, S.E.M., é “...algo tão cansativo e dispendioso compensa porque é divertido e mantém uma tradição na comunidade.” (conversa realizada em 13.01.2018). A festa não tem finalidade econômica, lembra uma delas. A tarefa de "armação do presépio" foi confiada a B. S. J. por uma tia que faleceu ainda quando era criança.

A festa de Reis conjuga duas versões, a festa de "Reis Pobres" e de "Reis Ricos". A distinção das festas de Reis na comunidade entre "Reis Pobres" e "Reis Ricos" tem sua origem no processo de ocupação e organização territorial pelos diferentes grupos. Os escravos fugidos das fazendas ali se encontravam formando um quilombo, daí aquela afirmação de que o Maracanã se constituiu de um “antigo quilombo". Como nesse período, os ex-escravos não tinham condições materiais, saiam nas casas dos moradores pedindo auxílio para realização da festa de Reis, esta é origem da festa de "Reis Pobres". A festa de "Reis Ricos", por sua vez, se origina das famílias que vieram posteriormente a área, comprando pequenos lotes e terrenos para ali se estabelecer.

Entretanto, essa distinção, que marcava as diferenças entre os moradores "pobres" e "ricos", não persiste nos dias de hoje. Ela perdura, contudo, como uma forma de lembrança de um passado remoto, já que todos "brincam" igualmente nas festas.

"Aqui é muito místico" (conversa com E., realizada em 20.05.2017) é a forma encontrada por E. para expressar essas maneiras de viver, de criar e de fazer na comunidade do Maracanã. As festas de Reis, assim como tantas outras

presépio são juntadas e queimadas em meio a cânticos e ladainhas. Essa festa tem um sentido religioso e comemorativo. 
festas da comunidade ${ }^{19}$, emergem de uma experiência coletiva historicamente construída. Além de serem uma manifestação de caráter religioso, é uma prática de lazer, pois congrega parentes, vizinhos e amigos, que compartilham esses momentos de renovação dos vínculos e dos compromissos em torno da defesa do território.

Acontecimentos mais recentes na comunidade pós-construção dos conjuntos, envolvendo "furtos de juçara" e roubo nas casas ${ }^{20}$, vêm obrigando uma postura mais vigilante dos moradores, bem como estratégias de proteção. Em uma das festas de reis, por exemplo, os organizadores cercaram o espaço da festa para uma maior vigilância e controle de pessoas estranhas à comunidade do Maracanã, dos conjuntos do PMCMV, diante das ameaças sofridas. Isso não se constituiu em um fechamento da festa à participação de outras pessoas, já que “todas são bem vindas".

Os cercamentos dos espaços das casas, pelo visto, têm se constituído de uma prática de proteção dos moradores, dos juçarais, dos cultivos e dos objetos, imprescindíveis às garantias de reprodução das maneiras de viver da comunidade. Entretanto, vale ressaltar que esses cercamentos, não significa um processo de isolamento ou fechamento da comunidade, no sentido de evitar quaisquer tipos de relacionamento com o Outro. Trata-se de uma convivência que alterou o cotidiano da comunidade, por isso mesmo cheia de desconfianças e de cuidados.

As festas revelam outro detalhe, que as atividades culturais e religiosas estão articuladas a forma de como a comunidade representa e se relaciona com a natureza. Em meio às conversas, uma "mãe de santo" e outra moradora, aquela organizadora da festa de "Reis", relataram que recebem entidades defensoras da mata e que essas têm clamado por "cuidados com a natureza que sofre com os maus tratos".

Os juçarais na região ocultam cursos d'água denominados brejos que, para os moradores locais, são redutos da "mãe d'água". Esses seres encantados que habitam as matas estariam ameaçados porque as águas estão "sumindo" por conta dos processos de assoreamento e morte dos rios, riachos e córregos, decorrentes da construção dos conjuntos do PMCMV. A imbricada relação com a natureza é expressa por B. S. J. (conversa realizada em 13.01.2018) nos versos abaixo transcritos:

19 Araújo (2012) identifica e descreve as diversas atividades culturais realizadas no período 1930-1970, que seriam constitutivas da identidade da comunidade do Maracanã. A expressão "Maracanã de antigamente", que é utilizada pelos moradores, segundo o autor, é enfatizada como forma de lembrar essas experiências e trajetórias.

20 Em algumas oportunidades, as conversas se dirigiam aos relatos de crimes e violências sofridos pelos moradores da comunidade. O estado de insegurança se contrapõe às memórias de um tempo de sossego e tranquilidade quando era possível "descansar com as portas abertas." 
O nosso rio tá seco

Os peixes foram embora

O que será, meu Deus, de nós agora!

Os versos cantados por B. S. J. era para lembrar de um sonho. Nele, a "mãe d'água" revelava toda a sua dor com a morte da natureza e clamava por ajuda. $\mathrm{Na}$ condição de vidente, B. S. J., é o veículo por meio do qual os caboclos da mata ("Conceição da Piedade" e "Rei Leão da Mata") se servem para alertar sobre os problemas vividos que colocam em risco a natureza.

Em outros espaços da comunidade, como no quintal da casa de S. J., em meio aos juçarais e as plantas, rezas e oferendas são oferecidas a Oxóssi, como agradecimentos e pedidos de "proteção à natureza que se vê ameaçada", são dirigidos a ele no ritual (conversa com S. J., realizada em 13.01.2018).

Essas experiências locais de uma religiosidade que conecta o mundo dos encantados com a natureza a partir de um saber prático informado por entidades, orientam uma relação da comunidade com o lugar, mas também expressa um "modelo de natureza" (ESCOBAR, 2005) ${ }^{21}$. Neste artigo, Arturo Escobar lembra a importância do trabalho feminino no desenvolvimento de "práticas baseadas no lugar" que ele denominou de "modelos culturais da natureza". Na situação da comunidade do Maracanã, as mulheres desempenham um papel preponderante na produção e reprodução dos saberes e das práticas relacionadas à natureza. Ao manter a conexão entre a natureza e o sagrado, elas dão continuidade a um entendimento necessário para a sobrevivência da própria comunidade.

Nesse modelo, os encantados são os "donos" e os "cuidadores" da natureza, sendo que as pessoas devem agir em conformidade com essas lógicas. Esse agir, contudo, implica em compreender o funcionamento da natureza, que ocorre "ascultando" as entidades, por meio da intuição, da observação, dos sonhos e da incorporação de entidades nos rituais que ocorrem nos terreiros. As pesquisas desenvolvidas por Nicolas Floriani et. al. (2016), sobre os sistemas faxinais no Paraná, também identificam situações parecidas às analisadas, onde a natureza e o sagrado se constituem de uma mesma entidade.

Os saberes sobre a natureza apreendidos e difundidos em circunstancias especiais vinculadas a uma relação de proximidade, de parentesco espiritual, "filiação", se aproximam dos processos descritos por Almeida (2008) de uma "territorialidade específica". Em outras palavras, os "modelos de natureza" circunscritos às "práticas socioespaciais" determinam um domínio próprio sobre o território, que opõe aos "projetos globais" e a toda forma de "alisamento".

21 Esses modelos se distanciam do modelo hegemônico, hoje, globalizado. Apresentada como vantagem comparativa dos países, a natureza é exposta em um portfólio para ser apropriada e vendida (CORONIL, 2005). 


\section{NÓS E OS OUTROS: “HISTÓRIAS LOCAIS" E "PROJETOS GLOBAIS"}

A situação da comunidade do Maracanã, descrita acima, encontrase inserida nessa lógica global, dominada pelo capital financeiro, que tem a habitação como uma das últimas fronteiras de acumulação (SASKEN, 2015). Recorda Rolnik (2015) que esse programa de construções de moradia, PMVMV, foi entregue à iniciativa privada, que adotou como estratégia a compra de terrenos mais baratos ${ }^{22}$, sobretudo, aqueles situados em locais distantes das áreas mais urbanizadas para a edificação de casas a população de baixa renda. A escolha dos terrenos tornou-se um dos elementos imprescindíveis para a obtenção de maior rentabilidade, na medida em que foi deixado todo o poder de decisão às construtoras, que vai desde a arquitetura dos projetos à localização.

Tal modelo popular de habitação, que se impõe pela padronização, escala, rapidez e localização, produz uma nova forma de "periferização organizada", sob a orientação exclusiva do mercado imobiliário, financeirizado. Assim, a urbanização e o adensamento da área do Maracanã decorrente dessa política habitacional vêm gerando sofrimentos aos moradores da comunidade do Maracanã, como a devastação das matas, poluição, assoreamento, morte dos rios, riachos e córregos etc. Somados a esses problemas que comprometem a reprodução física e cultural da comunidade, outros tantos surgiram como resultado da densificação populacional na área do Maracanã. A rede de infraestrutura e de serviços, que já era precária, se manteve, agora, sobrecarregada, sem conseguir atender as demandas avolumadas.

Importa ressaltar que a expansão urbana da cidade São Luís ocorre em dois eixos perpendiculares, já descritos pelos autores em outro trabalho (SHIRAISHI NETO et al., 2018). Um, em direção ao porto de Itaqui, caracterizado principalmente pelas atividades industriais e, outro eixo, em direção aos municípios de São José de Ribamar e Raposa, com forte atividade imobiliária, ainda que não exclusiva. Acompanhando a beira mar, os condomínios Alphaville e Dahma "dão o tom" da expansão, isto é, "escolhem” os seus vizinhos, com a cumplicidade do Poder Público. Deste outro lado da cidade, longe das praias, as ocupações e os conjuntos do Programa Minha Casa Minha Vida (PMCMV) dominam a paisagem que até pouco tempo era caracterizada como zona rural.

Muito embora essa expansão venha absorvendo parte da área rural em direção aos outros municípios da região metropolitana, observa-se um intenso

\footnotetext{
22 Na Região Metropolitana de São Luís, o referido programa teve sua trajetória marcada pela fragmentação, disperso nos municípios situados na ilha do Maranhão, sobretudo em São José de Ribamar e Paço do Lumiar, mais especificamente na faixa periurbana dos municípios e na zona rural de São Luís.
} 
processo de densificação imobiliária no espaço intra-urbano da cidade de São Luís. Nos interstícios da malha urbana figuram diferentes empreendimentos imobiliários que compreendem condomínios fechados, horizontais e verticais, sendo estes últimos, os de maior expressão.

Tais situações, determinadas pelos empreendimentos econômicos privados, vêm sendo pensadas a partir de um entendimento de "modernização" da cidade e do urbano, que se efetiva através de projetos de intervenções do Poder Público municipal e estadual. As obras de infraestrutura realizadas por esses poderes se efetivam, no sentido de privilegiar frações da cidade, já valorizadas, pela iniciativa privada.

Vale recordar os estudos de Carlos Vainer (2011) sobre as intervenções urbanas no Rio de Janeiro quando da realização dos jogos olímpicos. Elas, segundo Vainer, revelam o deslocamento das políticas urbanas, que, orientada pelo e para o mercado ("market oriented"), tendem a ignorar as concepções de cidade e de planejamento urbano expressos na Constituição Federal de 1988 e na Lei no 10.257/2001 (o denominado Estatuto da Cidade). Os processos, que se assemelham, sinalizam para a enorme capacidade dos "novos agentes" na determinação e condução das políticas urbanas no Brasil.

\section{4 À GUISA DE CONCLUSÃO}

As tentativas de apreender os saberes e as práticas da comunidade do Maracanã tiveram como referência os processos nos quais a mesma se encontra inserida, principalmente, as estratégias práticas que os moradores vêm se utilizando para se repensar e buscar novos sentidos às suas vidas, em rápida e intensa transformação.

Submetida a uma lógica que se impôs, com uma força extremamente desigual, comparativamente às condições reunidas pela comunidade, essa se vê obrigada a uma convivência com "outros", aqui entendidos como toda sorte de "estranhos", desde os próprios empreendimentos imobiliários, na sua enorme extensão e devastação, à grande quantidade de novos moradores, com as suas distintas representações da natureza, que chegaram, mudando a rotina e o cotidiano dos moradores antigos.

Tomados de assalto por uma ordenação urbana do espaço de São Luís, em contraposição a um quase mundo rural, com as suas formas de vida e relação com a natureza, esse antigo tecido sócio-cultural-ambiental se viu esgarçado e atravessado por novas teias que desafiam a comunidade a uma nova política de convivências. 
Os saberes e as práticas já enraizados, assumem agora, um poder capaz de negociar o lugar, como abertura, e ao mesmo tempo, como elementos de territorialização, já que definem e asseguram o lugar das pessoas e das coisas. A ameaça de rompimento abrupto da relação da comunidade com os seus vínculos (terra, sagrado, juçarais, buritizais, águas etc.), produz enormes sofrimentos aos moradores e são estes sofrimentos que, paradoxalmente, impulsionam as lutas que ocorrem em várias frentes. As festas e as rezas autorizam, assim, uma forma de conivência que não excluí o "outro", de modo que lhes permitem continuar, ainda que não da mesma forma, as suas tradições.

\section{REFERÊNCIAS}

ACSELRAD, Henri. As práticas espaciais e o campo dos conflitos ambientais. In: Conflitos Ambientais no Brasil. Rio de Janeiro: Relume Dumará: Fundação Heinrich Boll, 2004. pp.13-35.

ALMEIDA, Alfredo Wagner Berno de. Terra de quilombo, terras indígenas, "babaçuais livre", "castanhais do povo", faxinais e fundos de pastos: terras tradicionalmente ocupadas. $2^{\circ}$ ed. Manaus: PGSCA-UFAM, 2008.

ALMEIDA, Alfredo Wagner Berno de.; SHIRAISHI NETO, Joaquim; MARTINS, Cynthia Carvalho. Guerra Ecológica nos Babaçuais: O processo de devastação dos palmeirais, a elevação do preço de commodities e o aquecimento do mercado de terras na Amazônia. São Luís: Lithograf, 2005.

AMARAl FILHO, Jair. A Economia Política do Babaçu: um estudo da organização daextrato - indústria do babaçu no Maranhão e suas tendências. São Luís: SIOGE, 1990.

CORONIL, Fernando. Natureza do pós colonialismo: do eurocentrismo ao globocentrismo. In: LANDER, Edgard (org.). A colonialidade do saber: eurocentrismo e ciências sociais perspectivas latino - americanas. Argentina: CLACSO, 2005. pp. 50-62.

ESCOBAR, Arturo. La Invención del Tercer Mundo. Construción e descontrución del desarrollo. Caracas: Fundación Editorial el perro y la rana, 2007.

O lugar da natureza e a natureza do lugar: globalização ou pósdesenvolvimento? In: LANDER, Edgard (org.). A colonialidade do saber: eurocentrismo e ciências sociais perspectivas latino - americanas. Argentina: CLACSO, 2005. pp.63-79. 
FLORIANI, Nicolas; CUNHA, Lúcia Helena de Oliveira; VEIGA, Andrea Mayer; GALDINO, José Roberto de Vasconcelos. A Floresta e a Territorialidade Faxinalense: espaço sagrado, espaço de lutas. In: BASSOLS, Narcisio Barrera; FLORIANI, Nicolas (orgs.). Saberes, paisagens e territórios rurais da América Latina. Curitiba: Ed. UFPR, 2016. pp.199-217.

LIMA, Rosirene Martins. Conflitos Socioambientais em Curitiba. São Luís: editora UEMA, 2008a.

O Rural no Urbano. Uma análise da produção do espaço urbano de Imperatriz- MA. Imperatriz: Ética editora, 2008b.

LIMA, Rosirene Martins; SHIRAISHI NETO, Joaquim. Conflitos Socioambientais. O direito ambiental como instrumento de legitimação das ações de intervenção do poder público. Intervenção no Jardim Icaraí, Curitiba, PR. In: FLORIANI, Dimas; HEVIA, Antonio Elizarde (orgs.). América Latina: sociedade e meio ambiente: teorias, retóricas e conflitos em desenvolvimento. Curitiba: Ed. UFPR, 2016.

MBEMBE, Achille. Necropolitica. In: Necropolitica seguido de Sobre o Gobierno Privado Indirecto. Espanha: Melusina, 2006. pp.19-75.

MIGNOLO, Walter. Historias locales/ diseños globales. Colonialidad, conocimentos subalternos y pensamiento fronterizo. Espanha: Ediciones Akal, 2003.

OLIVEIRA FILHO, João Pacheco de. O Caboclo e o Brabo. Notas sobre duas modalidades de força de trabalho na expansão da fronteira Amazônica no século XIX. Encontros com a Civilização Brasileira, n. 11, pp. 101-140, 1979.

ROLNIK, Raquel. Guerra dos Lugares: a colonização da terra e da moradia na era das finanças. São Paulo: Boitempo, 2015.

SANTOS, Roberto. História Econômica da Amazônia (1800-1920). São Paulo: T. A. Queiroz, 1980.

SHIRAISHI NETO, Joaquim. Direito dos Povos e das Comunidades Tradicionais no Brasil: Declarações, Convenções e Dispositivos Jurídicos definidores de uma Política Nacional. $2^{\circ}$ ed. Manaus: UEA Edições, 2010. Quebradeiras de coco: "babaçu livre" e reservas extrativistas. Revista Veredas. Belo Horizonte, vol.14, n.28, pp. 147-166, janeiro/abril de 2017. 
SHIRAISHI NETO, Joaquim; LIMA, Rosirene Martins; SERRA, Sergio Lopes. A Cidade em Disputa: São Luís sob a ordem do capital financeiro. [São Luís]: s. ed., 2018. 19p.

VAINER, Carlos. Cidade de Exceção: reflexões a partir do Rio de Janeiro. 2011. Disponível em: https://br.boell.org/sites/default/files/downloads/carlos_ vainer_ippur_cidade_de_excecao_reflexoes_a_partir_do_rio_de_janeiro.pdf. Acesso em: 08 de agosto de 2017.

WACQUANT, Loic. Os condenados da cidade. Rio de Janeiro: Revan, 2001.

\section{Sobre a Comunidade do Maracanã}

ARAUJO, Marcelo de Sousa. A Identidade em Movimento: um estudo sobre a comunidade do Maracanã (1930-1970). 2012. Dissertação (Mestrado em Cultura e Sociedade). PPGCULT- UFMA, São Luís, 2012.

CYSNE, Ana Lenira; SANTOS, Jorge Hamilton dos; PEREIRA, Edileia Dutra. A Bacia Hidrográfica como Unidade de Planejamento Socioambiental: caracterização geomorfológica e hidrográfica da sub-bacia do Maracanã. São Luís-MA. In: XVI Encontro Nacional de Geógrafos, 2010, Porto Alegre. Anais... Porto Alegre: UFPB, 2010.

D’ABBVILLE, Claude. História da Missão dos Padres Capuchinhos na Ilha do Maranhão e terras circunvizinhas. São Paulo: Ed. Da Universidade de São Paulo, 1975.

\section{Documentos, Reportagens, Entrevistas e Vídeos}

ALMEIDA, Rogério; MASSON, Nonato. Maranhão: sistema penitenciário entrou em colapso. São Luís, 2014. Disponível em https://www.cartamaior. com.br/?/Editoria/Politica/Maranhao-sistema-penitenciario-entrou-emcolapso-/4/29990. Acesso em: 06 de dez. de 2017. 
